\title{
Enthalpies of formation of the benzyloxyl, benzylperoxyl, hydroxyphenyl radicals and related species on the potential energy surface for the reaction of toluene with the hydroxyl radical
}

\author{
Oscar N. Ventura ${ }^{1 *}$, Martina Kieninger ${ }^{1}$, Zoi Salta ${ }^{2}$, Agnie M. Kosmas $^{3}$, and Vincenzo Barone ${ }^{2}$ \\ ${ }^{1}$ Computational Chemistry and Biology Group, CCBG, DETEMA, Facultad de Química, Udelar, Montevideo, \\ Uruguay \\ ${ }^{2}$ SMART Lab, Scuola Normale Superiore di Pisa, Piazza dei Cavalieri, 7, 56126 Pisa, Italy \\ ${ }^{3}$ Physical Chemistry Sector, Department of Chemistry, University of loannina, loannina, Greece
}

The reaction of toluene (T) with $\mathrm{OH}^{\bullet}$ produces addition products as well as the benzyl radical (TR). TR can react with $\mathrm{OH}^{\bullet}$ or $\mathrm{O}_{2}$ to produce oxygenated species, for many of which there is no experimental information available. We present here theoretically determined heats of formation (HFs) of 17 such species using the non-isodesmic reactions on the potential energy surface (PES) of $\mathrm{TR}+\mathrm{O}_{2}$ and $\mathrm{T}+\mathrm{OH}^{\bullet}+\mathrm{O}_{2}$. For those species the experimental HFs of which are known, we obtained a good correlation between experimental and theoretical values at the G4 $\left(r^{2}=0.999\right)$ and M06/cc-pVQZ $\left(r^{2}=0.997\right)$ levels, thus showing the goodness of the methods used. Previously unknown HFs of other radicals (benzyloxyl, spiro [1,2-dioxetane benzyl], hydroxyphenyl, and benzylperoxyl) and closed shell species (salicylic alcohol, benzo[b]oxetane and $p$-hydroxy cyclohexa-2,5dienone) were later determined using those methods.

*Corresponding author:

Prof. Oscar N. Ventura

Computational Chemistry and Biology Group

CCBG - DETEMA

Facultad de Química, UdelaR

CC1157, 11000 Montevideo Uruguay

Tel. +59899501368

E-mail: Oscar.N.Ventura@gmail.com

ORCID:

$\begin{array}{ll}\text { Martina Kieninger } & \text { 0000-0002-5255-7148 } \\ \text { Zoi Salta } & \text { 0000-0002-7826-0182 } \\ \text { Agnie M. Kosmas } & \text { 0000-0003-4089-6254 } \\ \text { Oscar N Ventura } & \text { 0000-0001-5474-0061 } \\ \text { Vincenzo Barone } & \text { 0000-0001-6420-4107 }\end{array}$

Keywords:

Toluene; Atmospheric chemistry; Benzyl radical; Enthalpies of formation; DFT 


\section{Introduction}

Gas-phase tropospheric chemistry of organic species is a sub-area of research within atmospheric chemistry that has received considerable attention in recent times [1]. Because of the ubiquity of the hydroxyl radical, $\mathrm{OH}^{\bullet}$, its reaction with organic compounds (especially aromatics) in the atmosphere is of particular interest [2-4].

Toluene is the simplest aromatic molecule including an aliphatic moiety, which allows competitive hydrogen abstraction and ring addition of $\mathrm{OH}^{\bullet}$ to occur. It is also one of the main anthropogenic aromatic molecules in the atmosphere, due to car's exhaust, solvent use, and biomass burning. Therefore, its reactions have been studied repeatedly, both experimentally and theoretically. A non-exhaustive list of recent studies can be found in references [5-11]. We have recently performed a detailed study of the possible routes for the reaction of toluene (T) with $\mathrm{OH}^{\bullet}$, and further reactions of the intermediate radicals with both $\mathrm{OH}^{\bullet}$ and $\mathrm{O}_{2}[12,13]$. Several intermediates were identified theoretically, for which scarce or no experimental information is available. Among other things, there is no information about their enthalpies of formation. At the same time, other intermediates have been well characterized before, and their experimental enthalpies of formation are available. Since all these species lie on the same potential energy surface (PES), we considered interesting to assess the accuracy of some theoretical methods that can be applied to this system, using already known experimental enthalpies of formation for some of them. We used afterwards the most accurate of those methods to predict the unknown enthalpies of formation of the rest of the compounds.

In this paper we report a study on the enthalpies of formation of such species, using several methods and non-isodesmic reactions of formation, either from toluene, hydroxyl radical and oxygen, or benzyl radical and oxygen. In some cases, water molecules are also participating in the mechanisms and have been included in the reactions employed to calculate the enthalpies of formation of the species.

\section{Computational Methods}

Very accurate molecular properties can be obtained if, for instance, the $\operatorname{CCSD}(T)$ method is used at the complete basis set (CBS) limit. This method, however, is only possible for small molecules and less accurate approximations have often to be used. The simplest post-Hartree-Fock method including dynamical correlation energy is $2^{\text {nd }}$ order Møller-Plesset (MP2) perturbation theory [14, 15]. However, several failures of this method have been reported $[16,17]$ during the many years it has been in use. We used MP2 in this work in combination with a sufficiently large Pople's 6$311++G(3 d f, 2 p d)$ basis set, in order to evaluate whether it is accurate enough for the calculation of critical points on the aforementioned PES.

Special combinations of methods and basis sets, generally described as chemical models or model chemistries, have been developed to approximate $\operatorname{CCSD}(\mathrm{T}) / \mathrm{CBS}$ calculations, resorting to 
additive single-point contributions to the total energy, which take into account the effects of basis set enlargement and improved methods for calculating the correlation energy. These models are accurate enough for the description of chemical reactions (affording relative energies accurate to 1 or $2 \mathrm{kcal} / \mathrm{mol}$, which is generally known as chemical precision). Two of these chemical models have been used in this work to obtain the enthalpies of formation of the species shown in Figs. 1, 2 and 3 (species studied are highlighted in the mechanism of Fig. 1). On the one hand, the CBS-QB3 method of Peterson et al $[18,19]$ uses B3LYP [20] optimized geometries and frequencies, adding corrections to the complete basis set limit, and correlation effects at the single point CCSD(T) level. Both an empirical and a spin correction are added to obtain the final result. On the other hand, the G4 method of Curtiss et al [21] was used. In this method, geometries and frequencies are obtained at the B3LYP/6-31G(2df,p) level and the basis set effect is computed including diffuse and polarization functions in single point calculations. Correlation contributions are taken into account through a series of single point MP4 and $\operatorname{CCSD}(T)$ calculations and, finally, a semiempirical high-level correction ( $\mathrm{HLC}$ ) is added to the results. Both the CBS-QB3 and G4 methods estimated average errors in several properties for a large series of molecules are around $1 \mathrm{kcal} / \mathrm{mol}$ and recent papers have been published on benchmark calculations using these methods for calculating enthalpies of formation of closed-shell molecules and radicals $[22,23]$

Finally, density functional theory (DFT) [24] was used to obtain optimum geometries and thermodynamic functions. Many different DFT methods exist, and several papers have been published recently on the accuracy of such procedures [25-34]. Based on our previous experience $[25,36]$, we have chosen the M06 method [37], one of the components of the Minnesota functional suite, by Truhlar and collaborators. The method depends on a series of parameters optimized with different basis sets. It is known that DFT methods exhibit a smaller dependence on the basis sets than post-Hartree-Fock methods. However, the effect may be non-negligible. Since this is a factor that may influence our own results, we tried a limited variety of basis sets. Analogously to the MP2 calculations, we chose the $6-311++G(3 d f, 2 p d)$ basis set as the standard option, but we performed also calculations using a smaller basis, $6-31+G(d, p)$ and a more extended one, the cc-pVQZ Dunning basis set, to assess the dependence of our results on the basis set [38].

All calculations have been performed using Gaussian 09 [39]. Tight thresholds were used for geometry optimizations and the ultrafine grid was used for the numerical evaluation of integrals. The standard rigid rotator/harmonic oscillator approximation was used to compute thermochemical properties. Due to their cost and the relatively small contribution to the energies, no anharmonicity corrections were included in the calculations. All optimized structures were checked to be true minima by inspection of the eigenvalues of the Hessian.

\section{Results and Discussion}

\subsection{Simple reactions}

Since in this work we need to provide a reasonable description of the electronic structure of closed shell molecules (like toluene or benzaldehyde) and open-shell species, we performed some tests of the chemical models used, addressing some very simple reactions intended to represent situations like the ones found in the real systems. Enthalpies of formation of the 
closed shell water and formaldehyde molecules, and of free radicals $\mathrm{HOO}^{\bullet}$ and $\mathrm{CH}_{3}{ }^{\bullet}$ were calculated employing the reactions

$$
\begin{aligned}
& \mathrm{H}^{\bullet}+\mathrm{OH}^{\bullet} \rightarrow \mathrm{H}_{2} \mathrm{O} \\
& 2 \mathrm{H}^{\bullet}+\mathrm{O} \rightarrow \mathrm{H}_{2} \mathrm{O} \\
& \mathrm{H}_{2}+\mathrm{O} \rightarrow \mathrm{H}_{2} \mathrm{O} \\
& \mathrm{H}_{2}+1 / 2 \mathrm{O}_{2} \rightarrow \mathrm{H}_{2} \mathrm{O} \\
& \mathrm{H}^{\bullet}+\mathrm{O}_{2} \rightarrow \mathrm{HOO}^{\bullet} \\
& \mathrm{OH}^{\bullet}+\mathrm{O} \rightarrow \mathrm{HOO}^{\bullet} \\
& 1 / 2 \mathrm{H}_{2}+\mathrm{O}_{2} \rightarrow \mathrm{HOO}^{\bullet} \\
& \mathrm{CH}_{4}+\mathrm{O}_{2} \rightarrow \mathrm{CH}_{3}^{\bullet}+\mathrm{HOO}^{\bullet} \\
& \mathrm{CH}_{4}+\mathrm{OH}^{\bullet} \rightarrow \mathrm{CH}_{3}^{\bullet}+\mathrm{H}_{2} \mathrm{O} \\
& \mathrm{CH}_{4}+\mathrm{O}_{2} \rightarrow \mathrm{CH}_{2} \mathrm{O}+\mathrm{H}_{2} \mathrm{O} \\
& \mathrm{CH}_{2} \mathrm{O}+\mathrm{OH}^{\bullet} \rightarrow \mathrm{CH}_{3}+\mathrm{O}_{2}
\end{aligned}
$$

Since these are all small systems, we included also calculations at the QCISD(T) [40] and $\operatorname{CCSD}(T$, Full) $[40,41]$ levels which are normally more accurate than MP2. All species were assumed to be in their ground states and the geometries were optimized using each chemical model independently. The experimental enthalpies of formation of reactants and products needed to calculate $\Delta_{f} H_{298}^{o}$ of the four species were taken from reference [42]. The errors of each calculation with respect to the experimental $\Delta_{f} H_{298}^{o}$ of the species are collected in Table 1.

\section{INSERT TABLE 1}

Values in Table 1 are organized as follows. For each of the four species considered, a column shows the absolute value of the difference between the theoretical and experimental $\Delta_{f} H_{298}^{O}$ for each method and the corresponding basis set. The final columns show the average deviation for each model, over the whole set of eleven reactions, and the error on this value obtained as two times the standard deviation. These parameters are used to appraise the average accuracy of the methods used. At the bottom of the table, the average with respect to all methods for each reaction is taken, including and excluding MP2 results which in most cases are the worst ones. These numbers are used to appraise the average errors of the theoretical predictions for each reaction.

As expected, the error varies with the chemical model and the reaction considered. In general, MP2 calculations are not very reliable for the radicals; errors as high as $11.2 \mathrm{kcal} / \mathrm{mol}$ were found. There is no systematic way of assessing the error for these specific reactions, but in general, the addition of a larger fraction of correlation energy in $\mathrm{QCISD}(\mathrm{T})$ and $\operatorname{CCSD}(\mathrm{T})$ calculation lowers the average error and its dispersion. Careful addition of basis set and correlation energy effects in composite methods lower the average error and its spread, from $4.3 \mathrm{kcal} / \mathrm{mol}$ in MP2 to $0.7 \mathrm{kcal} / \mathrm{mol}$ in $\mathrm{G} 4$. For the reactions studied, the $\mathrm{G} 4$ error varies in the interval [0.0-1.9] kcal/mol. Analogously, the M06 calculations using the $6-311++\mathrm{G}(3 \mathrm{df}, 2 \mathrm{pd})$ basis set perform as well as $\mathrm{G} 4$, with errors in the interval [0.1-2.0] $\mathrm{kcal} / \mathrm{mol}$. However, notice that 
the enlargement of the basis set does not assure a better result, something that seems to be a general feature of DFT methods (see, for instance, reference 35). According to the results in this table then, one could expect that results at the $\mathrm{G} 4$ and M06 levels would be mostly in the range $[-2,+2] \mathrm{kcal} / \mathrm{mol}$ around the experimental data.

\subsection{Enthalpy of formation of the benzyl radical TR}

The mechanisms studied in our work on the reaction between toluene and $\mathrm{OH}^{\bullet}$ are shown in Fig. $1[12,13]$. We framed there those species that are studied in this paper, in black for those with known experimental enthalpy of formation, and in red for the other ones.

\section{INSERT FIGURE 1}

Since our ultimate goal is to assess the expected accuracy of our methods on the PES for the reaction starting from $\mathrm{T}$ and $\mathrm{OH}^{\bullet}$ and proceeding further from the benzyl radical (TR), T and TR were the species we studied first. We have collected in Fig. 2 some important parameters of their optimum geometries. In the case of $\mathrm{T}$, the first entry corresponds to the experimental geometry determined by Amir-Ibrahimi et al. [43]. There is no accurate experimental information on TR. However, Noble-Eddy attempted a mixed procedure in his Ph.D. Thesis [44], using electron diffraction data to refine $\mathrm{MP2} / 6-311++\mathrm{G}(\mathrm{d}, \mathrm{p})$ calculations. As far as we are aware, the best theoretically optimized geometries were those obtained by Kortyna et al. [45] at the $\operatorname{CCSD}(T)-f 12 b / c c p V T Z-f 12$ level. Both sets of results were included in Fig. 2.

\section{INSERT FIGURE 2}

All the theoretical results for $\mathrm{T}$ are in qualitative agreement among themselves concerning the order of the bond lengths. The $\mathrm{C} 1-\mathrm{C} 7$ bond length is the longest, followed by $\mathrm{C} 1-\mathrm{C} 2$ and $\mathrm{C} 2-$ C3. C3-C4 is almost equal to C2-C3 but slightly longer. The theoretical calculations provide shorter bond lengths than the experimental ones, with the M06/cc-pVQZ results systematically being the smallest ones. For TR the situation is different. The mixed experimental-theoretical results of Noble-Eddy [45] suggest the same order of bond lengths than in T, namely C1-C7 > C1$\mathrm{C} 2>\mathrm{C} 2-\mathrm{C} 3<\mathrm{C} 3-\mathrm{C} 4$. However, only the MP2 theoretical calculations exhibit this ordering. The best theoretical results of Kortyna et al. [24], as well as our own DFT calculations, suggest that C1-C7 is considerably shorter than C1-C2. Moreover, the semi-experimental values for these two bonds are much larger than those obtained from the theoretical calculations. It is possible that Noble-Eddy semi-experimental results are not very accurate, and therefore probably further experimental work is needed on this subject.

The reactions employed to obtain the enthalpy of formation of the benzyl radical are the following

$$
\begin{aligned}
& \mathrm{T}+\mathrm{OH}^{\bullet} \rightarrow \mathrm{TR}+\mathrm{H}_{2} \mathrm{O} \\
& \mathrm{T}+\mathrm{CH}_{3}^{\bullet} \rightarrow \mathrm{TR}+\mathrm{CH}_{4}
\end{aligned}
$$


Both are isodesmic reactions and we showed above that the theoretically calculated values obtained for $\mathrm{H}_{2} \mathrm{O}$ and $\mathrm{CH}_{4}$ employing these radicals are reasonably accurate. For both these reasons, one would expect to get good error cancellation and to obtain reasonable values of $\Delta_{f} H_{298}^{o}$. Experimental values needed to calculate the enthalpies of formation of TR were obtained from the Thermochemical Data Tables [42] in the case of $\mathrm{OH}^{\bullet}(8.96 \mathrm{kcal} / \mathrm{mol}), \mathrm{H}_{2} \mathrm{O}(-$ $57.80 \mathrm{kcal} / \mathrm{mol}), \mathrm{CH}_{3}{ }^{\bullet}(35.00 \mathrm{kcal} / \mathrm{mol}), \mathrm{CH}_{4}(-17.81 \mathrm{kcal} / \mathrm{mol})$ and $\mathrm{T}(12.01 \mathrm{kcal} / \mathrm{mol})$. The experimental value of the enthalpy of formation of TR $(49.71 \pm 0.41 \mathrm{kcal} / \mathrm{mol})$ was taken from reference [46] and used to evaluate the error of the calculations. The value preferred by Ruscic et al. [46] was actually obtained as the weighted average of both experimental and theoretically calculated values, but it is almost identical with the average of the experimental values only. It should be taken into account that the experimental value is not unique, but lies on a range from $48.5 \pm 1.4 \mathrm{kcal} / \mathrm{mol}$ [47] to $50.3 \pm 1.0 \mathrm{kcal} / \mathrm{mol}$ [48], so that the experimental interval can be considered to be [47.1-51.3] kcal/mol. At present the most widely accepted value is that recommended by Tsang [49], $49.4 \pm 1.0 \mathrm{kcal} / \mathrm{mol}$.

\section{INSERT TABLE 2}

The first observation is that, as expected on the basis of the above calculations on simple molecules and radicals, MP2 results are extremely bad. This is a consequence of two things. On one side, the lack of enough electronic correlation in the representation of the geometrical and electronic structure of TR. This conclusion is supported by the CBS-QB3 and G4 results. Although the geometry optimization is performed at the B3LYP level in both cases, the inclusion of higher orders of correlation energy (MP4, CCSD(T)) improves the energy results, giving errors below the $2.0 \mathrm{kcal} / \mathrm{mol}$ limit. The second reason is the high spin contamination of the UMP2 calculations. In fact, the UMP2/6-311++G(2df,2pd) calculation of TR at the optimum minimum geometry affords $a\left\langle s^{2}\right\rangle$ value of 1.26 for $S=0.73$, before annihilation of the first spin contaminant, and $\left\langle s^{2}\right\rangle=0.98$ after it. These values differ markedly from the correct $\left\langle s^{2}\right\rangle=0.75$ for the doublet radical $(S=0.5)$. On the other side, the concept of spin contamination is not completely meaningful at the DFT level, because of the absence of a comparable wavefunction. Even so, an analogous M06 calculation gives values of $\left\langle s^{2}\right\rangle=0.79$ for $S=0.52$, i.e. much nearer to the theoretical value. Although it is then clear that MP2 calculations will not be useful for the study, we keep also these results to point out some fortuitous agreement of the calculations with the experiments. In order not to clutter the paper with non-significant results, we included all the MP2 calculations (except for TR) in Table SI1 of the Supplementary Information section.

All the values obtained for $\Delta_{f} H_{298}^{o}(\mathrm{TR})$ with the other methods are within the experimental range. M06 values are generally as good as the CBS-QB3 or G4 results, independently of the basis set used. The choice of the reaction is not indifferent. While the CBS-QB3 and G4 results are nearer to the experimental data when reaction (2) is used rather than (1), the opposite is true for the M06 calculations. In general, the former methods overestimate the enthalpy of formation of TR, while the M06 calculations underestimate it, considering the average experimental value. These trends suggest the empirical working hypothesis that the average of G4 and M06/cc-pVQZ values should provide a reasonable approximation to the experimental 
enthalpy of formation. In the case of TR, this average gives 50.4 and $49.5 \mathrm{kcal} / \mathrm{mol}$ using reactions (1) and (2) respectively, in both cases within $1.0 \mathrm{kcal} / \mathrm{mol}$ from the average experimental value. Moreover, the W1 value communicated privately by Martin to Ruscic et al. [46], was $49.3 \pm 1.0 \mathrm{kcal} / \mathrm{mol}$, in nice agreement with our own values.

\subsection{Enthalpy of formation of species on the PES of TR $+\left[\mathrm{OH}^{\circ}, \mathrm{O}_{2}\right]$}

Fig. 2 shows the structures of the nine additional radical and closed shell species involved in the mechanism we studied, and for which experimental data are available. Their geometric and energetic characteristics will be briefly described in the following.

The geometry of the simplest aryl radical, phenyl radical (I), was determined only recently by Martinez et al. [50]. They used a combination of rotational spectroscopy of singly substituted isotopic species and vibrational corrections calculated theoretically, to obtain what they called a semi-experimental structure. Large CCSD(T)/cc-CV5Z calculations were also performed, allowing the comparison with purely theoretical results. It is clear from the calculated parameters (see I in Fig. 3) that these CCSD(T)/cc-CV5Z calculations give a geometrical structure very similar to the experimental one, but also that the G4 and M06/cc-pVQZ calculations give comparable results. MP2 calculations, on the contrary, give poor geometries.

In this paper, we used the non-isodesmic reactions

$$
\begin{aligned}
& \mathrm{TR}+\mathrm{O}_{2} \rightarrow(\mathrm{I})+\mathrm{O}+\mathrm{CH}_{2} \mathrm{O} \\
& \mathrm{T}+\mathrm{OH}^{\bullet}+\mathrm{O}_{2} \rightarrow(\mathrm{I})+\mathrm{O}+\mathrm{CH}_{2} \mathrm{O}+\mathrm{H}_{2} \mathrm{O}
\end{aligned}
$$

to obtain the enthalpy of formation of (I) at all levels of theory. The experimental value of the enthalpy of formation was recently corrected by Stevens et al. [51] to $80.5 \pm 0.1 \mathrm{kcal} / \mathrm{mol}$. The theoretical values we obtained from reactions (14) and (15) are in general lower than the experimental one. G4, particularly using reaction (15), is closer than M06 to the experimental result. Notice that reaction (14) has an open shell radical on the right hand side which may unbalance it, while the errors related to triplet oxygen atom may cancel with those on the triplet oxygen molecule on the left hand side. Reaction (15), with one open shell radical on both sides of the equation, should be better balanced, a conjecture supported by the G4 calculations, but not by the M06 ones.

Benzoyl radical (II) has been recently studied by Sebbar et al. [52]. They performed B3LYP/6$311 \mathrm{G}(\mathrm{d}, \mathrm{p})$ and G3MP2B3 calculations of the reaction of II with $\mathrm{O}_{2}$. In the course of this study, they determined values of the enthalpy of formation of II as $30.70 \pm 2.1 \mathrm{kcal} / \mathrm{mol}$ (B3LYP) and $30.12 \pm 0.56 \mathrm{kcal} / \mathrm{mol}$ respectively. The experimental value was determined by Simões and Griller [53] using photoacoustic calorimetry, obtaining $\Delta_{f} H_{298}^{o}=27.72 \pm 2.60 \mathrm{kcal} / \mathrm{mol}$, which overlaps with the theoretical value. Our own values for this radical (see Table 2 ) were obtained as $28.8 \pm 1.6 \mathrm{kcal} / \mathrm{mol}(\mathrm{G} 4)$ and $32.6 \pm 2.4 \mathrm{kcal} / \mathrm{mol}$ (M06/cc-pVQZ). Both values are larger than 
the experimental value, but they overlap when the error bars are considered. They also overlap with the theoretical values of Sebbar et al. [52] obtained as averages of values derived from the enthalpies of several reactions. In our case, the enthalpies of formation were obtained as the average of the results from the non-isodesmic reactions

$$
\begin{aligned}
& \mathrm{TR}+\mathrm{O}_{2} \rightarrow(\mathrm{II})+\mathrm{H}_{2} \mathrm{O} \\
& \mathrm{T}+\mathrm{OH}^{\bullet}+\mathrm{O}_{2} \rightarrow(\mathrm{II})+2 \mathrm{H}_{2} \mathrm{O}
\end{aligned}
$$

The G4 result for reaction (5) differs by $0.4 \mathrm{kcal} / \mathrm{mol}$ from the experimental one, while the error of reaction (6) is a bit larger. This does not occur with the M06 method, which gives the same value for both reactions, although it is about $5 \mathrm{kcal} / \mathrm{mol}$ too high.

The phenoxyl radical (III) was also studied experimentally by Walker and Tsang [47] who found a formation enthalpy of $13.22 \mathrm{kcal} / \mathrm{mol}$. A careful experimental and theoretical study performed recently by Simões et al. [54], afforded a formation enthalpy of $13.26 \pm 0.57$ $\mathrm{kcal} / \mathrm{mol}$, very near to the previous one. Our own results were obtained using the non-isodesmic reactions

$$
\begin{aligned}
& \mathrm{TR}+\mathrm{O}_{2} \rightarrow(\mathrm{III})+\mathrm{CH}_{2} \mathrm{O} \\
& \mathrm{T}+\mathrm{OH}^{\bullet}+\mathrm{O}_{2} \rightarrow(\mathrm{III})+\mathrm{H}_{2} \mathrm{O}+\mathrm{CH}_{2} \mathrm{O}
\end{aligned}
$$

As seen in Table SI1, MP2 again fails badly for reaction (19). However, it gives a surprisingly good enthalpy of formation from reaction (18), undoubtedly a fortuitous result (the same as observed for the phenyl radical). G4 gives results within $1 \mathrm{kcal} / \mathrm{mol}$ from the experimental value, while the M06 calculations give much too low values.

The rest of the species considered, whose experimental values are known, are closed shell molecules, namely benzaldehyde (IV), benzyl alcohol (V), phenol (VI), p-benzoquinone (VII), catechol (VIII), and benzoic acid (IX). Experimental results, references and the reactions from which we obtained the enthalpies of formation in this work, are the following:

IV, benzaldehyde, $\Delta_{f} H_{298}^{o}=8.83 \pm 0.22 \mathrm{kcal} / \mathrm{mol}[42]$,

$$
\begin{aligned}
& \mathrm{TR}+\mathrm{O}_{2} \rightarrow(\mathrm{IV})+\mathrm{OH}^{\bullet} \\
& \mathrm{T}+\mathrm{O}_{2} \rightarrow(\mathrm{IV})+\mathrm{H}_{2} \mathrm{O}
\end{aligned}
$$

V, benzyl alcohol, $\Delta_{f} H_{298}^{o}=-22.6 \pm 0.72 \mathrm{kcal} / \mathrm{mol}[66]$

$$
\begin{aligned}
& \mathrm{TR}+\mathrm{OH}^{\bullet} \rightarrow(\mathrm{V}) \\
& \mathrm{T}+2 \mathrm{OH}^{\bullet} \rightarrow(\mathrm{V})+\mathrm{H}_{2} \mathrm{O}
\end{aligned}
$$

VI, phenol, $\Delta_{f} H_{298}^{o}=-23.04 \pm 0.22 \mathrm{kcal} / \mathrm{mol}$ [56]. Dorofeeva and Ryzhova [57] recently reexamined the enthalpy of formation of phenol, reporting alleged inconsistencies between 
the theoretically derived values and Cox experimental one [56]. They recommended a lower value, $-21.94 \pm 0.6 \mathrm{kcal} / \mathrm{mol}$, but we used Cox's value anyway for assessing the errors of our calculations.

$$
\begin{aligned}
& \mathrm{TR}+\mathrm{O}_{2}+\mathrm{H}_{2} \mathrm{O} \rightarrow(\mathrm{VI})+\mathrm{OH}^{\bullet}+\mathrm{CH}_{2} \mathrm{O} \\
& \mathrm{T}+\mathrm{O}_{2} \rightarrow(\mathrm{VI})+\mathrm{CH}_{2} \mathrm{O}
\end{aligned}
$$

VII, p-benzoquinone, $\Delta_{f} H_{298}^{o}=-27.7 \pm 3.0 \mathrm{kcal} / \mathrm{mol}[58]$,

$$
\begin{aligned}
& \mathrm{TR}+2 \mathrm{O}_{2} \rightarrow(\mathrm{VII})+\mathrm{OH}^{\bullet}+\mathrm{CH}_{2} \mathrm{O} \\
& \mathrm{T}+2 \mathrm{O}_{2} \rightarrow(\mathrm{VII})+\mathrm{CH}_{2} \mathrm{O}+\mathrm{H}_{2} \mathrm{O}
\end{aligned}
$$

VIII, catechol, $\Delta_{f} H_{298}^{o}=-65.68 \pm 0.29 \mathrm{kcal} / \mathrm{mol}[59]$

$$
\begin{aligned}
& \mathrm{TR}+\mathrm{O}_{2}+\mathrm{OH}^{\bullet} \rightarrow(\mathrm{VIII})+\mathrm{CH}_{2} \mathrm{O} \\
& \mathrm{T}+\mathrm{O}_{2}+2 \mathrm{OH}^{\bullet} \rightarrow(\mathrm{VIII})+\mathrm{CH}_{2} \mathrm{O}+\mathrm{H}_{2} \mathrm{O}
\end{aligned}
$$

IX, benzoic acid, $\Delta_{f} H_{298}^{o}=-73.01 \mathrm{kcal} / \mathrm{mol}$ [60] (obtained using the enthalpy of formation of the solid and the enthalpy of sublimation)

$$
\begin{aligned}
& \mathrm{TR}+\mathrm{O}_{2}+\mathrm{OH}^{\bullet} \rightarrow(\mathrm{IX})+\mathrm{H}_{2} \mathrm{O} \\
& \mathrm{T}+\mathrm{O}_{2}+2 \mathrm{OH}^{\bullet} \rightarrow(\mathrm{IX})+2 \mathrm{H}_{2} \mathrm{O}
\end{aligned}
$$

All the results we obtained for these molecules, including the errors with respect to the experimental values, are reported in Table 3. Considering these nine species plus the benzyl radical, the average error obtained with the G4 method was $1.1 \mathrm{kcal} / \mathrm{mol}$ and with the M06/cc-pVQZ, $2.3 \mathrm{kcal} / \mathrm{mol}$. We assigned twice the average of these two errors as the expected accuracy of our predictions.

It is interesting to make some comparisons between the experimental and calculated values of the enthalpies of formation for these species, particularly in those cases where different molecules show similar $\Delta_{f} H_{298}^{o}$. The first observation is that all methods reported in Table 3 show the same ordering of the enthalpies of formation, with that of the phenyl radical being the most positive one, and that of benzoic acid the most negative. $A$ comparison of the phenyl radical and benzaldehyde, with similar positive enthalpies of formation, shows that CBS-QB3, G4 and M06/cc-pVQZ exhibit the correct ordering, in agreement with experiment, whereas M06 with the smaller basis sets does not. This is another argument in favor of calculations with the larger set at the M06 level. Two other species which exhibit very similar enthalpies of formation are benzyl alcohol and phenol, which experimentally differ by only $0.4 \mathrm{kcal} / \mathrm{mol}$ in favor of phenol. One sees in the table that all methods predict correctly the ordering, although the difference is (in all cases except CBS-QB3) larger than in the experiment. 


\section{INSERT TABLE 3}

Fig. 4 shows the correlation between the experimental and the theoretically derived enthalpies of formation. Each marker is located at the intersection of the experimental and theoretical value for each species and method. As mentioned before, the MP2 values (either with respect to TR or with respect to $T$, see Table SI1) are bad. The linear correlation shown in this figure deviates much from the $X=Y$ diagonal corresponding to perfect agreement between computation and experiment. G4 and M06/cc-pVQZ calculations, on the other hand, show a very reasonable agreement with experiment. The regression lines for these two methods, in $\mathrm{kcal} / \mathrm{mol}$, obey the equations

G4: $\quad \Delta_{f} H_{298}^{o}($ theor $)=0.9902 \Delta_{f} H_{298}^{o}(\exp )+0.8151, r^{2}=0.999$

M06/cc-pVQZ: $\Delta_{f} H_{298}^{o}($ theor $)=0.9838 \Delta_{f} H_{298}^{o}(\exp )-0.3299, r^{2}=0.997$

These equations can be used to correct the raw values for the enthalpies of formation of unknown species participating in the oxidation of aromatics by $\mathrm{OH}$.

\section{INSERT FIGURE 4}

Table 4 contains the enthalpies of formation predicted for those species for which no experimental data are available (the optimized structures are shown in Fig. 2). The values given were obtained as averages of the extrapolated values obtained from the enthalpies of reaction with respect to TR and T, using equations (21) and (22), only for those two methods that behaved consistently well. The quoted error, as said before, is given as twice the average of the errors for G4 and M06/cc-pVQZ enthalpies of formation of species (I)(IX) and TR. The actual error is probably lower.

\section{INSERT TABLE 4}

The species, predicted enthalpies of formation and reactions employed in each case are presented in Table 5.

\section{INSERT TABLE 5}

To the best of our knowledge, the enthalpies of formation of these compounds have not been determined before, neither experimentally nor theoretically, except for a couple of cases. For salicylic alcohol, an approximate determination using the group-additivity Joback-Reid method [61] was published [62], giving a value of $-67.12 \mathrm{kcal} / \mathrm{mol}$ in good agreement with our recommended value. Da Silva and Bozzelli $[63,64]$, using a simpler theoretical method (G3B3) suggested a value of $31.1 \mathrm{kcal} / \mathrm{mol}$ for the benzyloxyl radical and $29.6 \mathrm{kcal} / \mathrm{mol}$ for the benzylperoxyl radical. Both values are larger than the best ones we found and, moreover, they suggest that the latter is more stable than the former, contrary to what we found. Approximate additive group calculations were used also by Bounaceur et al. [11] to determine the enthalpies of formation of the benzyl, benzylperoxyl and benzoyl 
radicals. Their values $(49.4,26.9$ and $26.0 \mathrm{kcal} / \mathrm{mol})$ are close to the more accurate ones we present in this paper. Finally, Fenter et al. [65] determined the forward rate constant and the equilibrium constant for the association reaction of the benzyl radical with oxygen, and derived an enthalpy of formation of $28.0 \pm 1.4 \mathrm{kcal} / \mathrm{mol}$ for the benzylperoxyl radical, in excellent agreement with our theoretical result. All this related information lend support to our procedure and the set of proposed enthalpies of formation we derived in this paper.

Reaction (46) is particularly interesting, because experimental data on its enthalpy of reaction have been published $[65,66]$. Adopting the same extrapolation procedure described before to correct the enthalpies of reaction at the G4 and M06/cc-pVQZ level and averaging these values, our result for the enthalpy of reaction is $-21.7 \pm 1.6 \mathrm{kcal} / \mathrm{mol}$. Elmaimouni et al. [66] studied the kinetics of the reaction of the benzyl radical with molecular oxygen between 393 and $433 \mathrm{~K}$. From the data obtained, they predicted $\Delta_{r} H_{298}^{o}$ $=-20 \pm 1 \mathrm{kcal} / \mathrm{mol}$. A little later, Fenter et al. [65] studied the kinetics and equilibrium of the benzyl radical association reaction with molecular oxygen and predicted $\Delta_{r} H_{298}^{o}=-21.8 \pm$ $1.0 \mathrm{kcal} / \mathrm{mol}$. Our theoretical value is in excellent agreement with both experimental results.

\section{Conclusions}

Quantum mechanical calculations have been performed on radicals and closed shell species lying on the potential energy surface of the reaction of benzyl radical with $\mathrm{O}_{2}, \mathrm{OH}^{\bullet}$, and $\mathrm{H}_{2} \mathrm{O}$. These species arise in different channels in the reaction mechanism of toluene reaction with the $\mathrm{OH}^{\bullet}$ radical (see, for instance, Metcalfe et al. [5], Murakami et al. [10], Bounaceur et al. [11] and ourselves $[12,13])$ and the enthalpies of formation were known for about half of the 17 compounds studied. Non-isodesmic reactions connecting products and reactants on these reaction paths, starting either from toluene or the benzyl radical, were used to calculate the enthalpies of formation.

When available, experimentally known enthalpies of formation were compared to those calculated theoretically. It was determined that the MP2 values were very unreasonable when the enthalpies of formation were calculated with respect to the benzyl radical. The results improved when the toluene molecule was employed, but the results were still unsatisfactory. Only in a few cases, like, e.g., hydroxyphenyl radical, the MP2 values are similar to the experimental ones, suggesting that this method is not adequate for the study of the oxidation of toluene (and possibly other aromatics) in atmospheric and combustion chemistry.

The other methods employed in this paper gave smaller errors. CBS-QB3 and G4 gave average errors between 1 and $2 \mathrm{kcal} / \mathrm{mol}$, independently of whether T or TR were used as reference. The M06 errors depended on the basis set used and showed a non-systematic behavior. Taking either T or TR as reference, the results obtained with the $6-311++G(3 d f, 2 p d)$ basis set were worse than those obtained with the simpler $6-31+G(d, p)$ basis set, probably because the former set, although larger, is not well balanced for DFT methods. The best results were obtained with the cc- 
pVQZ basis set. Notwithstanding that the M06/cc-pVQZ average error was larger than either CBSQB3 or G4, it is in the correct range $(2.3 \mathrm{kcal} / \mathrm{mol})$ and is independent of whether T or TR are used to determine the enthalpy of formation. Thus, M06/cc-pVQZ was determined to be an appropriate method for the study of the more complex PES.

Both G4 and M06/cc-pVQZ models were shown to perform pretty well for enthalpies of formation over a range of more than $120 \mathrm{kcal} / \mathrm{mol}$. The correlation between theoretical and experimental values exhibit very large correlation coefficients $\left(r^{2}=0.999\right.$ for $\mathrm{G} 4$ and 0.997 for M06/cc-pVQZ) and the slope of the lines are almost unity (0.990 for G4 and 0.984 for M06/cc-pVQZ). Therefore, it is proposed that these regression lines can be used to correct the results obtained with those methods.

Using the knowledge derived from the study of the species with known experimental enthalpies of formation, a prediction of these values for a set of radicals and closed shell species considered in the literature as intermediates or products in some of the reaction paths for the reaction of the benzyl radical with oxygen was performed. The values reported are the most accurate and, in most cases, the only ones available up to now in the literature.

In our opinion the procedure outlined and the results obtained represent a further step towards a deeper knowledge of the atmospheric chemistry of toluene. The newly determined set of enthalpies of formation may be useful in studies of combustion and atmospheric chemistry of this species. Some of the tested theoretical methods show promise for the extension of these studies to more complex systems.

\section{Acknowledgments}

PEDECIBA (Uy), CSIC (UdelaR, Uy) and ANII (Uy) are gratefully acknowledged for sustained funding of the theoretical atmospheric chemistry program in which the toluene project is included. Some of the calculations reported in this paper were performed in ClusterUY, a newly installed platform for high performance scientific computing at the National Supercomputing Center, Uruguay. 


\section{References}

[1] R. Atkinson, Gas-phase tropospheric chemistry of organic compounds: a review, Atmosph. Environ. 24A, 1990, 1-41.

[2] R. Atkinson, Kinetics and Mechanisms of the Gas-Phase Reactions of the Hydroxyl Radical with Organic Compounds under Atmospheric Conditions, Chem. Rev. 85, 1985, 69-201.

[3] Y. Yang, M. Shao, X. Wang, A. C. Nolscher, S. Kessel, A. Guenther, J. Williams, Towards a quantitative understanding of total $\mathrm{OH}$ reactivity: A review, Atmosph. Environ. 134, 2016, 147-161.

[4] M. Nayebzadeh, M. Vahedpour, A review on reactions of polycyclic aromatic hydrocarbons with the most abundant atmospheric chemical fragments: theoretical and experimental data, Prof. React. Kinet. Mech. 42, 2017, 201-220.

[5] W. K. Metcalfe, S. Dooley, F. I. Dryer, Comprehensive Detailed Chemical Kinetic Modeling Study of Toluene Oxidation, Energy Fuels 25, 2011, 4915-4936.

[6] C. O. Baltaretu, E. I. Lichtman, A. B. Hadler, M. J. Elrod, Primary Atmospheric Oxidation Mechanism for Toluene, J. Phys. Chem. A 113, 2009, 221-230.

[7] A. Hatipoglu, D. Vione, Yelda. Yalçin, C. Minero, Z. Çinar, Photo-oxidative degradation of toluene in aqueous media by hydroxyl radicals, J. Photochem. Photobiol. A, Chem. 215, 2010, 59-68.

[8] R. Wu, S. Pan, Y. Li, L. Wang, Atmospheric Oxidation Mechanism of Toluene, J. Phys. Chem. A. $118,2014,4533-4547$.

[9] Y. Ji, J. Zhao, H. Terazono, K. Misawa, N. P. Levitt, Y. Li, Y. Lin, Y. Peng, Y. Wang, L. Duan, B. Pan, F. Zhang, X. Feng, T. An, W. Marrero-Ortiz, J. Secrest, A. L. Zhang, K. Shibuya, M. J. Molina, R. Zhang, Reassesing the atmospheric oxidation mechanism of toluene, Proc. Nat. Acad. Sci. 114, 2017, 8169-8174.

[10] Y. Murakami, T. Oguchi, K. Hashimoto, Y. Nosaka, Theoretical Study of the Benzyl + O2 Reaction: Kinetics, Mechanism, and Product Branching Ratios, J. Phys. Chem. A 111, 2007, 13200-13208.

[11] R. Bounaceur, I. da Costa, R. Fournet, F. Billaud, F. Battin-Leclerc, Experimental and Modeling Study of the Oxidation of Toluene, Chem. Kinet. 37, 2005, 25-49.

[12] Z. Salta, A. M. Kosmas, M. E. Segovia, M. Kieninger, O. N. Ventura, V. Barone, A reinvestigation of the deceptively simple reaction of toluene with $\mathrm{OH}^{\bullet}$, and the fate of the benzyl radical. I. A combined thermodynamic and kinetic study on the competition between $\mathrm{HO}$-addition and $\mathrm{H}$-abstraction reactions, J. Phys. Chem. A, sent.

[13] Z. Salta, A. M. Kosmas, M. E. Segovia, M. Kieninger, O. N. Ventura, V. Barone, A reinvestigation of the deceptively simple reaction of toluene with $\mathrm{OH}^{\bullet}$, and the fate of the benzyl radical. II. The "secret" routes to cresols and benzaldehyde, J. Phys. Chem. A, sent.

[14] M. J. Frisch, M. Head-Gordon, and J. A. Pople, Direct MP2 gradient method, Chem. Phys. Lett. 166, 1990, 275-80.

[15] M. Head-Gordon and T. Head-Gordon, Analytic MP2 Frequencies Without Fifth Order Storage: Theory and Application to Bifurcated Hydrogen Bonds in the Water Hexamer, Chem. Phys. Lett., 220, 1994, 122-128, and references therein. 
[16] E. L. Coitiño, O. N. Ventura, Isomerization of the formaldehyde radical cation and the failure of MP2, Chem. Phys. Lett. 202, 1993, 479-482.

[17] E. Soydaş, U. Bozkaya, Assessment of Orbital-Optimized MP2.5 for Thermochemistry and Kinetics: Dramatic Failures of Standard Perturbation Theory Approaches for Aromatic Bond Dissociation Energies and Barrier Heights of Radical Reactions, J. Chem. Theory Comput. 11, 2015, 1564-1573, and references therein.

[18] J. A. Montgomery Jr., M. J. Frisch, J. W. Ochterski, G. A. Petersson, A complete basis set model chemistry. VI. Use of density functional geometries and frequencies, J. Chem. Phys., 110, 1999, 2822-27.

[19] J. A. Montgomery Jr., M. J. Frisch, J. W. Ochterski, G. A. Petersson, A complete basis set model chemistry. VII. Use of the minimum population localization method, J. Chem. Phys. 112, 2000, 6532-42.

[20] A. D. Becke, Density-functional thermochemistry. III. The role of exact exchange, J. Chem. Phys. 98, 1993, 5648-52.

[21] L. A. Curtiss, P. C. Redfern, and K. Raghavachari, Gaussian-4 theory, J. Chem. Phys. 126, 2007, 084108.

[22] K. P. Somers, J. M. Simmie, Benchmarking Compound Methods (CBS-QB3, CBS-APNO, G3, G4, W1BD) against the Active Thermochemical Tables: Formation Enthalpies of Radicals, J. Phys. Chem. A 119, 2015, 8922-8933.

[23] J. M. Simmie, K. P. Somers, Benchmarking Compound Methods (CBS-QB3, CBS-APNO, G3, G4, W1BD) against the Active Thermochemical Tables: A Litmus Test for Cost-Effective Molecular Formation Enthalpies, J. Phys. Chem. A 119, 2015, 7235-7246.

[24] W. Koch, M. C. Holthausen, A Chemists Guide to Density Functional Theory, 2001, Wiley.

[25] N. Mardirossian, M. Head-Gordon, Thirty years of density functional theory in computational chemistry: an overview and extensive assessment of 200 density functionals, Mol. Phys. 115, 2017, 2315-2372.

[26] J. A. van Santen, G. A. DiLabio, Dispersion Corrections Improve the Accuracy of Both Noncovalent and Covalent Interactions Energies Predicted by a Density-Functional Theory Approximation, J. Phys. Chem. A 2015, 119, 6703-6713.

[27] R. O. Jones, Density functional theory: Its origins, rise to prominence, and future, Revs. Mod. Phys. 2015, 87, 897-923.

[28] A. Sengupta, K. Raghavachari, Solving the density functional conundrum: Elimination of systematic errors to derive accurate reaction enthalpies of complex organic reactions, Org. Lett. 2017, 19, 2576-2579.

[29] A. D. Boese, Density functional theory and hydrogen bonds: are we there yet?, ChemPhysChem 2015, 16, 978-985.

[30] H. S. Yu, X. He, S. L. Li, D. G. Truhlar, MN15: A Kohn-Sham global-hybrid exchangecorrelation density functional with broad accuracy for multi-reference and single-reference systems and noncovalent interactions, Chem. Sci. 2016, 7, 5032-5051.

[31] S. Lehtola, C. Steigemann, M. J. T. Oliveira, M. A. L. Marques, Recent developments in libxcA comprehensive library of functionals for density functional theory, SoftwareX 2018, 7, 1-5.

[32] S. Grimme, P. R. Schreiner, Computational Chemistry: The Fate of Current Methods and Future Challenges, Angew. Chem. Int. Ed. 2018, 57, 4170-4176.

[33] A. Gulans, A. Kozhevnikov, C. Draxl, Microhartree precision in density functional theory calculations, Phys. Rev. B 2018, 97, 161105(R).

[34] D. Hait, M. Head-Gordon, How Accurate Is Density Functional Theory at Predicting Dipole Moments? An Assessment Using a New Database of 200 Benchmark Values, J. Chem. Theory Comput. 2018, 14, 1969-1981. 
[35] K. Irving, M. Kieninger, O. N. Ventura, Basis Set Effects in the Description of the Cl-O bond in $\mathrm{ClO}$ and $\mathrm{XClO} / \mathrm{ClOX}$ Isomers $(X=H, O$ and $\mathrm{Cl})$ Using DFT and CCSD(T) Methods, J. Chemistry, 2019, in press.

[36] G. Petsis, Z. Salta, A. M. Kosmas, O. N. Ventura, Theoretical study of the microhydration of 1-chloro and 2-chloro ethanol as a clue for their relative propensity toward dehalogenation, Int. J. Quantum Chem., 2019, accepted.

[37] Y. Zhao and D. G. Truhlar, The M06 suite of density functionals for main group thermochemistry, thermochemical kinetics, noncovalent interactions, excited states, and transition elements: two new functionals and systematic testing of four M06-class functionals and 12 other functionals, Theor. Chem. Acc., 120, 2008, 215-41.

[38] F. Jensen, Introduction to Computational Chemistry, $3^{\text {rd }}$ Ed., 2017, Wiley.

[39] Gaussian 09, Revision D.01, M. J. Frisch, G. W. Trucks, H. B. Schlegel, G. E. Scuseria, M. A. Robb, J. R. Cheeseman, G. Scalmani, V. Barone, B. Mennucci, G. A. Petersson, H. Nakatsuji, M. Caricato, X. Li, H. P. Hratchian, A. F. Izmaylov, J. Bloino, G. Zheng, J. L. Sonnenberg, M. Hada, M. Ehara, K. Toyota, R. Fukuda, J. Hasegawa, M. Ishida, T. Nakajima, Y. Honda, O. Kitao, H. Nakai, T. Vreven, J. A. Montgomery, Jr., J. E. Peralta, F. Ogliaro, M. Bearpark, J. J. Heyd, E. Brothers, K. N. Kudin, V. N. Staroverov, T. Keith, R. Kobayashi, J. Normand, K. Raghavachari, A. Rendell, J. C. Burant, S. S. Iyengar, J. Tomasi, M. Cossi, N. Rega, J. M. Millam, M. Klene, J. E. Knox, J. B. Cross, V. Bakken, C. Adamo, J. Jaramillo, R. Gomperts, R. E. Stratmann, O. Yazyev, A. J. Austin, R. Cammi, C. Pomelli, J. W. Ochterski, R. L. Martin, K. Morokuma, V. G. Zakrzewski, G. A. Voth, P. Salvador, J. J. Dannenberg, S. Dapprich, A. D. Daniels, O. Farkas, J. B. Foresman, J. V. Ortiz, J. Cioslowski, D. J. Fox, Gaussian, Inc., Wallingford CT, 2013.

[40] (a) John A. Pople; Martin Head-Gordon; Krishnan Raghavachari , "Quadratic configuration interaction. A general technique for determining electron correlation energies". J. Chem. Phys. 87, 1987, 35975; (b) George D. Purvis; Rodney J. Bartlett , "A full coupled-cluster singles and doubles model: The inclusion of disconnected triples". J. Chem. Phys. 76, 1982, 1910-1919.

[41] G. E. Scuseria and H. F. Schaefer III, "Is coupled cluster singles and doubles (CCSD) more computationally intensive than quadratic configuration-interaction (QCISD)?" J. Chem. Phys., 90 (1989) 3700-03, and references therein.

[42] B. Ruscic, R. E. Pinzon, M. L. Morton, G. von Laszewski, S. Bittner, S. G. Nijsure, K. A. Amin, M. Minkoff, and A. F. Wagner, Introduction to Active Thermochemical Tables: Several "Key" Enthalpies of Formation Revisited, J. Phys. Chem. A 108, 9979-9997 (2004) and references therein.

[43] V. Amir-Ebrahimi, A. Choplin, J. Demaison, G. Roussy, Microwave Spectrum of the ${ }^{13} \mathrm{C}-$ RingMonosubstituted Toluenes and Structure of Toluene, J. Mol. Spectrosc. 89, 1981, 42-52.

[44] R. Noble-Eddy, Gas-phase electron diffraction studies of unstable molecules, A thesis presented for the degree of Doctor of Philosophy in the College of Science and Engineering at the University of Edinburgh, 2009. Available from http://www.era.lib.ed.ac.uk/handle/1842/4101 (web site consulted Dec. 2017).

[45] A. Kortyna, A. J. Samin, T. A. Miller, D. J. Nesbitt, Sub-Doppler infrared spectroscopy of resonance stabilized hydrocarbon intermediates: $v_{3} / v_{4} \mathrm{CH}$ stretch modes and $\mathrm{CH}_{2}$ internal rotor dynamics of benzyl radical, Phys. Chem. Chem. Phys. 19, 2017, 29812-29821.

[46] B. Ruscic, J. E. Boggs, A. Burcat, A. G. Csaszar, J. Demaison, R. Janoschek, J. M. L. Martin, M. L. Morton, M. J. Rossi, J. F. Stanton, P. G. Szalay, P. R. Westmoreland, F. Zabel, T. Berces, 
IUPAC Critical Evaluation of Thermochemical Properties of Selected Radicals. Part I, J. Phys. Chem. Ref. Data, 34, 2005, 573-656.

[47] J. A. Walker, W. Tsang, Single-pulse shock tube studies on the thermal decomposition of nbutyl phenyl ether, n-pentylbenzene, and phenetole and the heat of formation of phenoxyl and benzyl radicals, J. Phys. Chem. 94, 1990, 3324-3327.

[48] H. Hippler, J. Troe, Thermodynamic Properties of Benzyl Radicals: Enthalpy of Formation from Toluene, Benzyl lodide, and Dibenzyl Dissociation Equilibria, J. Phys. Chem. 94, 1990, 3803-3806.

[49] W. Tsang, Heats of Formation of Organic Free Radicals by Kinetic Methods in Energetics of Organic Free Radicals, J. A. M. Simões, A. Greenberg, J. F. Liebman, eds., Blackie Academic and Professional, London, 1996, 22-58.

[50] O. Martinez, Jr., K, N. Crabtree, C. A. Gottlieb, J. F. Stanton, M. C. McCarthy, An Accurate Molecular Structure of Phenyl, the Simplest Aryl Radical, Angew. Chem. Int. Ed. 54, 2015, 1808-1811.

[51] W. R. Stevens, B. Ruscic, T. Baer, Heats of Formation of $\mathrm{C} 6 \mathrm{H} 5 \bullet$, C6H5+, and $\mathrm{C} 6 \mathrm{H} 5 \mathrm{NO}$ by Threshold Photoelectron Photoion Coincidence and Active Thermochemical Tables Analysis, J. Phys. Chem. A 114, 2010, 13134-13145.

[52] N. Sebbar, J. W. Bozzelli, H. Bockhorn, Thermochemistry and Reaction Paths in the Oxidation Reaction of Benzoyl Radical: $\mathrm{C}_{6} \mathrm{H}_{5} \mathrm{C}^{\circ}(=\mathrm{O})$, J. Phys. Chem. A 115, 2011, 11897-11914.

[53] J. A. M. Simões, D. Griller, Enthalpy of formation of the benzoyl radical by photoacoustic calorimetry, Chem. Phys. Letters 158, 1989, 175-177.

[54] R. G. Simões, F. Agapito, H. P. Diogo, M. E. Minas da Piedade, Enthalpy of Formation of Anisole: Implications for the Controversy on the $\mathrm{O}-\mathrm{H}$ Bond Dissociation Enthalpy in Phenol, J. Phys. Chem. A 118, 2014, 11026-11032.

[55] T. S. Papina, S. M. Pimenova, V. A. Luk'yanova, V. P. Kolesov, Standard enthalpies of formation of benzyl alcohol and $\alpha, \alpha, \alpha$-trichlorotoluene, Russ. J. Phys. Chem. (Engl. Transl.), 69, 1995, 1951-1953.

[56] J. D. Cox, The heats of combustion of phenol and the three cresols, Pure Appl. Chem. 2, 1961, 125-128.

[57] O. V. Dorofeeva, O. N. Ryzhova, Enthalpy of Formation and O-H Bond Dissociation Enthalpy of Phenol: Inconsistency Between Theory and Experiment, J. Phys. Chem. A 120 (2016) 24712479.

[58] A. Fattahi, S. R. Kass, J. F. Liebman, M. A. R. Matos, M. S. Miranda, V. M. F. Morais, The Enthalpies of Formation of $o-, m-$, and $p$-Benzoquinone: Gas-Phase Ion Energetics, Combustion Calorimetry, and Quantum Chemical Computations Combined, J. Am. Chem. Soc. 127, 2005, 6116-6122.

[59] R. Sabbah, E. N. L. E. Buluku, Thermodynamic study of three isomers of dihydroxybenzene, Can. J. Chem. 69, 1991, 481-488.

[60] R. Goton, E. Whalley, Thermodynamic properties of benzoic acid, Can. J. Chem. 34, 1956, 1506-1507.

[61] K. G. Joback. R. C. Reid, Estimation of Pure-Component Properties from Group-Contributions, Chem. Eng. Commun. 57, 1987, 233-243. 
[62] Cheméo website, see https://www.chemeo.com/cid/64-057-8/Salicyl\%20alcohol, visited $23^{\text {rd }}$ Dec. 2017.

[63] G. da Silva, M. R. Hamdan, J. W. Bozzelli, Oxidation of the Benzyl Radical: Mechanism, Thermochemistry, and Kinetics for the Reactions of Benzyl Hydroperoxide, J. Chem. Theor. Comput. 5, 2009, 3185-3194.

[64] G. da Silva, J. W. Bozzelli, Kinetic modeling of the benzyl $+\mathrm{HO}_{2}$ reaction, Proc. Combust. Instit. 32, 2009, 287-294.

[65] F. F. Fenter, B. Noziere, F. Caralp, R. Lesclaux, Study of the Kinetics and Equilibrium of the Benzyl-Radical Association Reaction with Molecular Oxygen, Int. J. Chem. Kinet. 26, 1994, 171-189.

[66] L. Elmaimouni, R. Minetti, J. P. Sawerysyn, P. Devolder, Kinetics and Thermochemistry of the Reaction of Benzyl Radical with 02: Investigations by Discharge Flowhaser Induced Fluorescence between 393 and 433 K, Int. J. Chem. Kinet. 25, 1993, 399-413.

[67] C.-W. Cheng, Y.-P. Lee, H. A. Witek, Theoretical Investigation of Molecular Properties of the First Excited State of the Phenoxyl Radical, J. Phys. Chem. A 112, 2008, 2648-2657.

[68] K. B. Borisenko, Ch. W. Bock, I. Hargittai, Molecular Geometry of Benzaldehyde and Salicylaldehyde: A Gas-Phase Electron Diffraction and Ab Initio Molecular Orbital Investigation, J. Phys. Chem. 100, 1996, 7426-7434. 


\section{Figures}

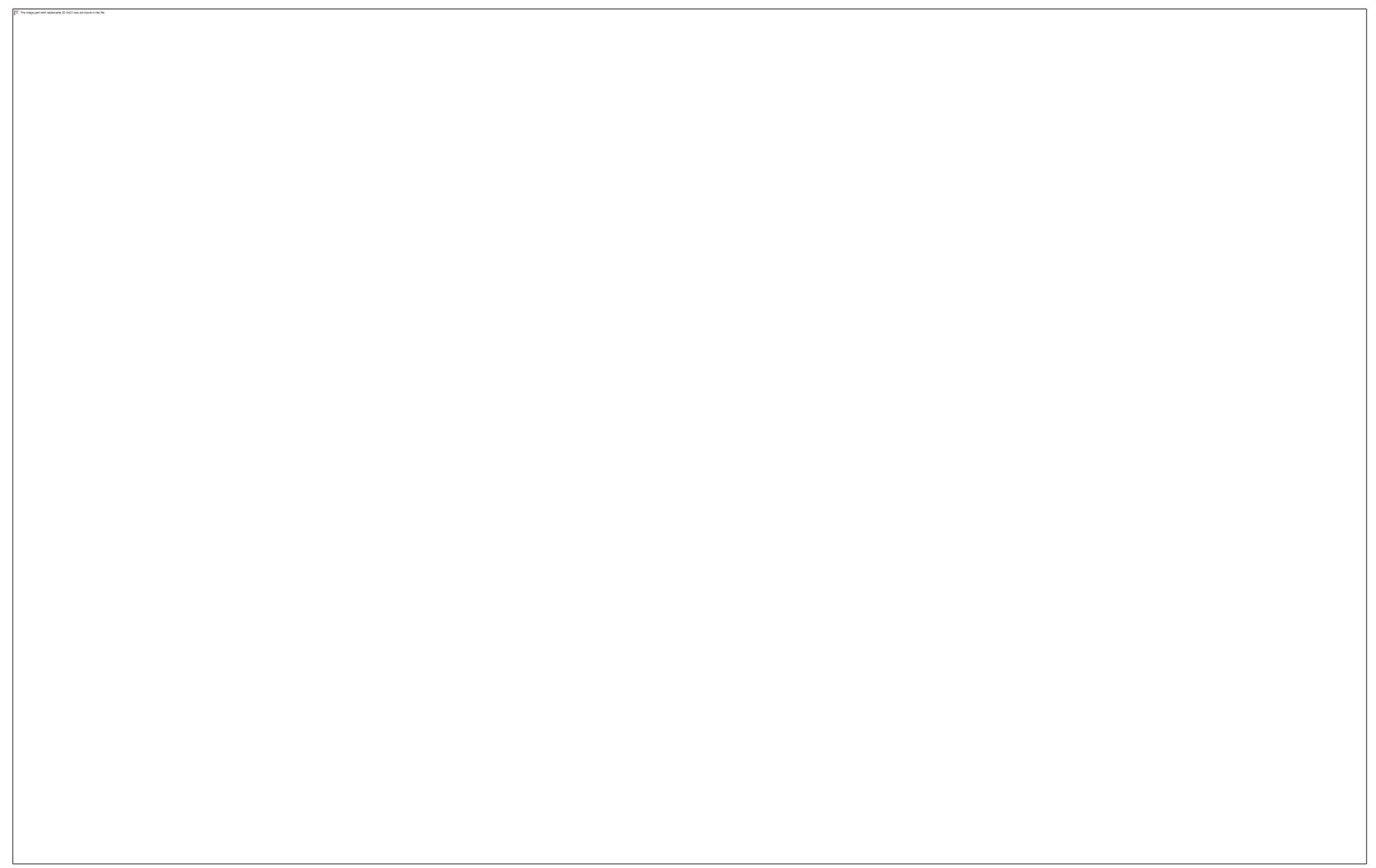

Figure 1. General scheme of the reactions of the benzyl radical (TR) with $\mathrm{OH}[11 \mathrm{a}, 11 \mathrm{~b}]$. Framed in black are the species which experimental enthalpy of formation is known. Species for which there exist no experimental information are framed in red. 


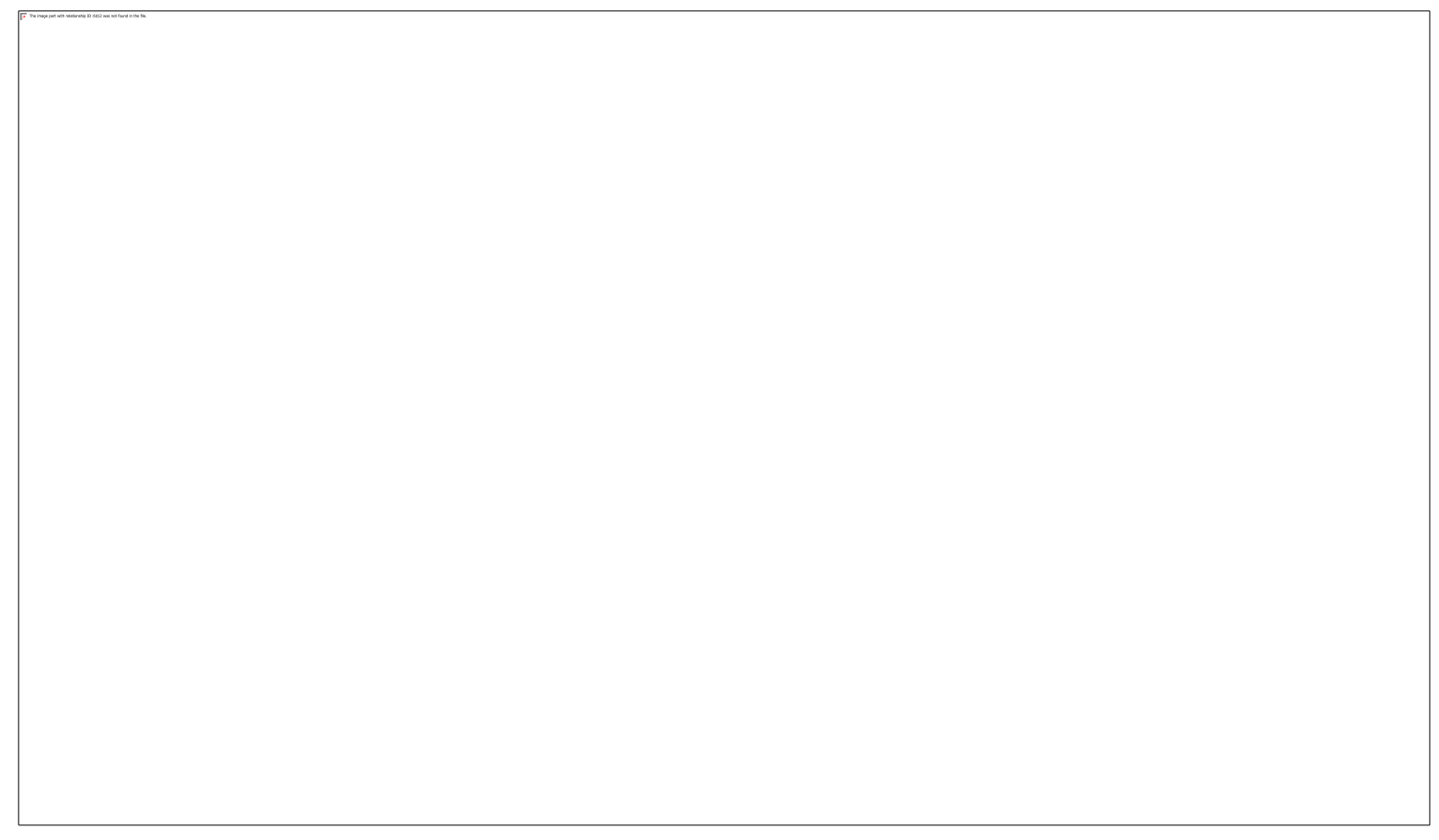

Figure 2. Most relevant geometrical parameters for T and TR ( $C_{2 v}$ symmetry in both cases). The first entry for T are the experimental values from ref. [43] (in black), second to fourth entries (dark red, italic) are MP2/6$311++\mathrm{G}(3 \mathrm{df}, 2 \mathrm{pd}), \mathrm{G} 4$ and M06/cc-pVQZ values calculated in this work, respectively. The first entry for TR (black) are the semi experimental values of ref. [44], second entry (black) the CCSD(T)-f12b/ccpVTZ-f12 results of ref. [45] and the third to fifth entries (dark red, italic) our own MP2, G4 and M06 results. Distances are in $\AA$ and bond angles in degrees. 

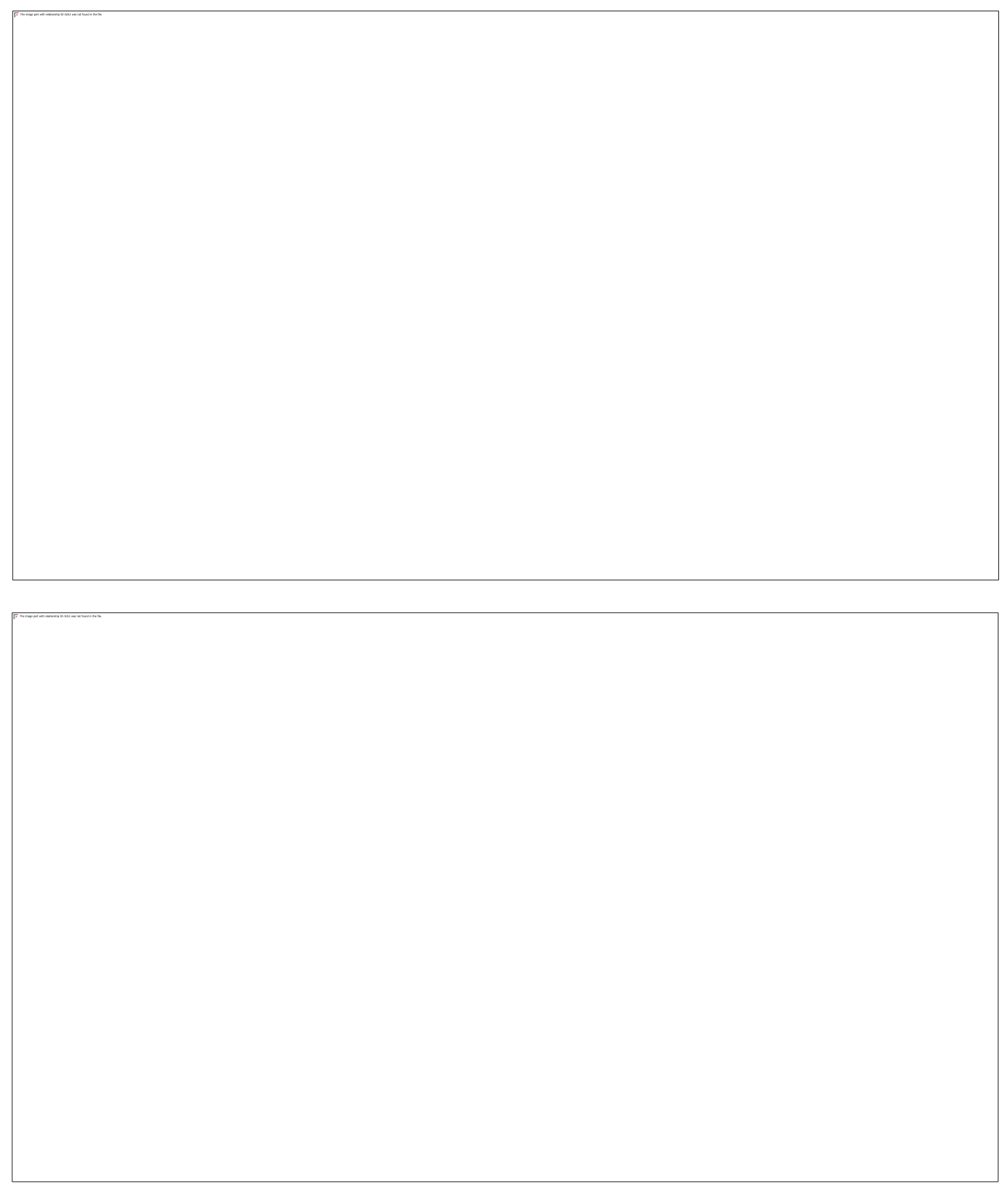

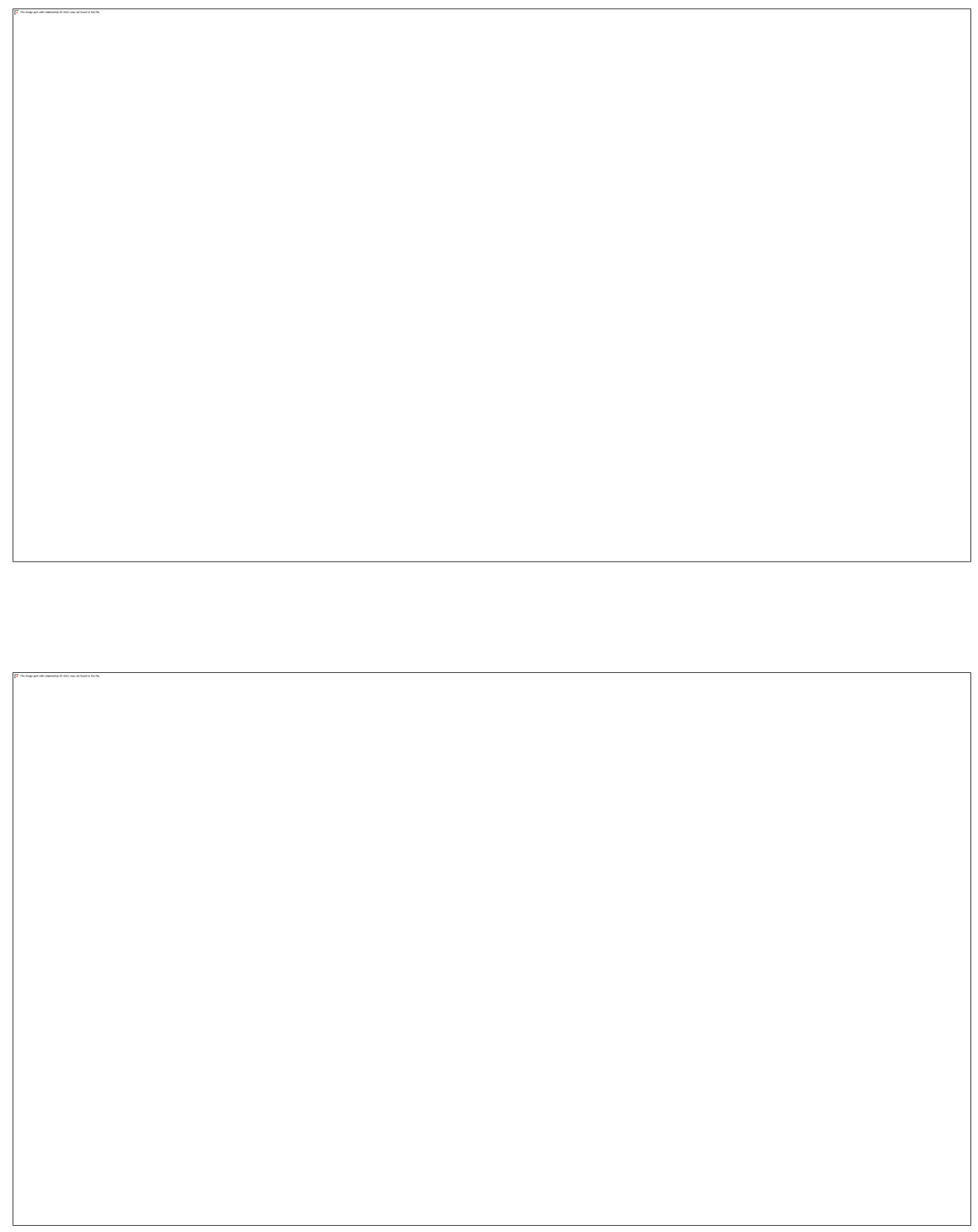

21 


$$
\text { 政 }
$$




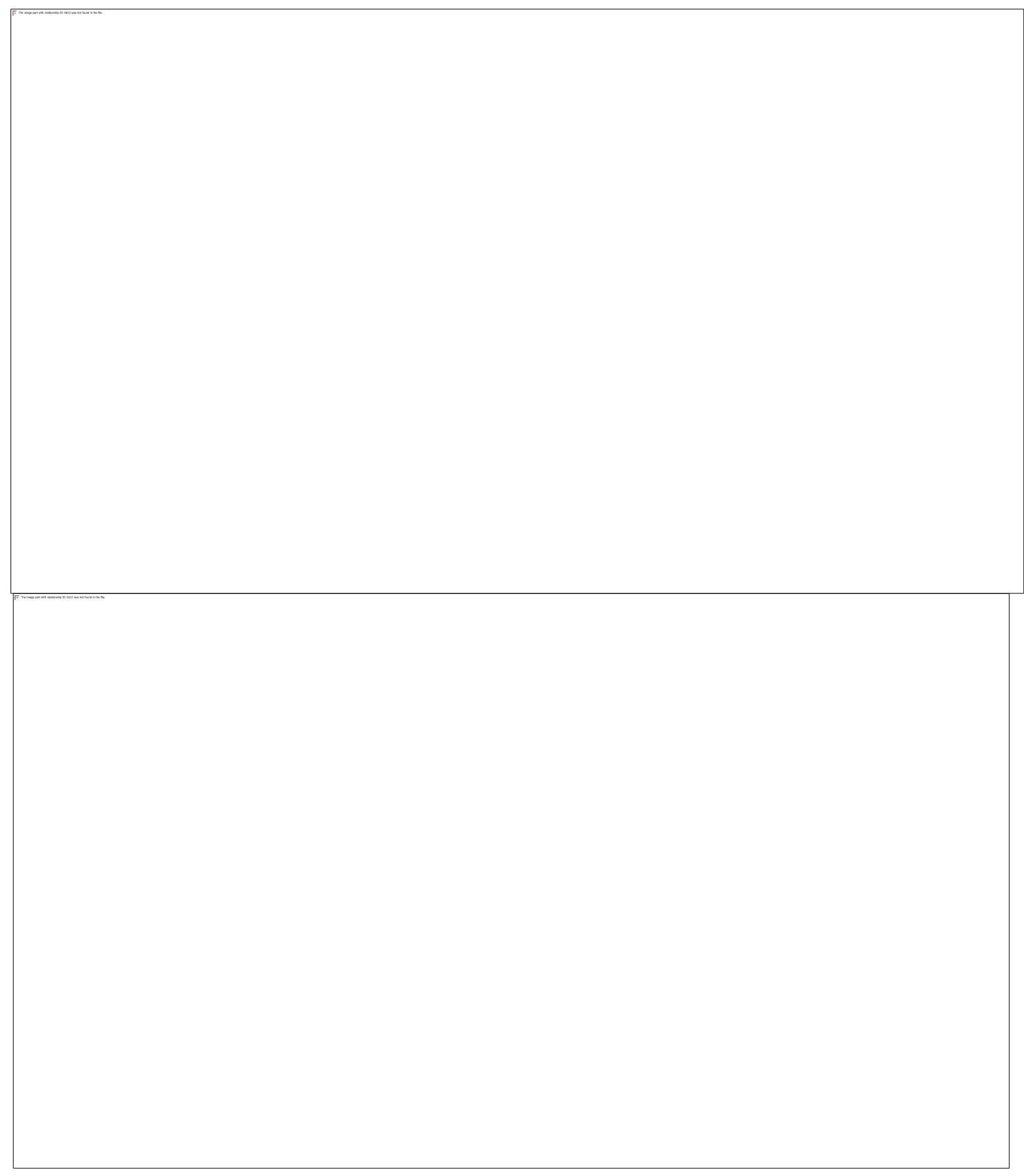

Figure 3. Structure of all the radicals and closed-shell species which enthalpies of formation were calculated with the methods used in this paper. Important optimized geometrical parameters are shown for the MP2/6$311++\mathrm{G}(3 \mathrm{df}, 2 \mathrm{pd}), \mathrm{G} 4$ and M06/cc-pVQZ calculations (first three entries); bond distances are given in $\AA$ and angles in degrees. Important theoretical or experimental information for the geometries are given as the last entries for some of the molecules: phenyl radical [49, 50], phenoxyl radical [67] and benzaldehyde [68]. 


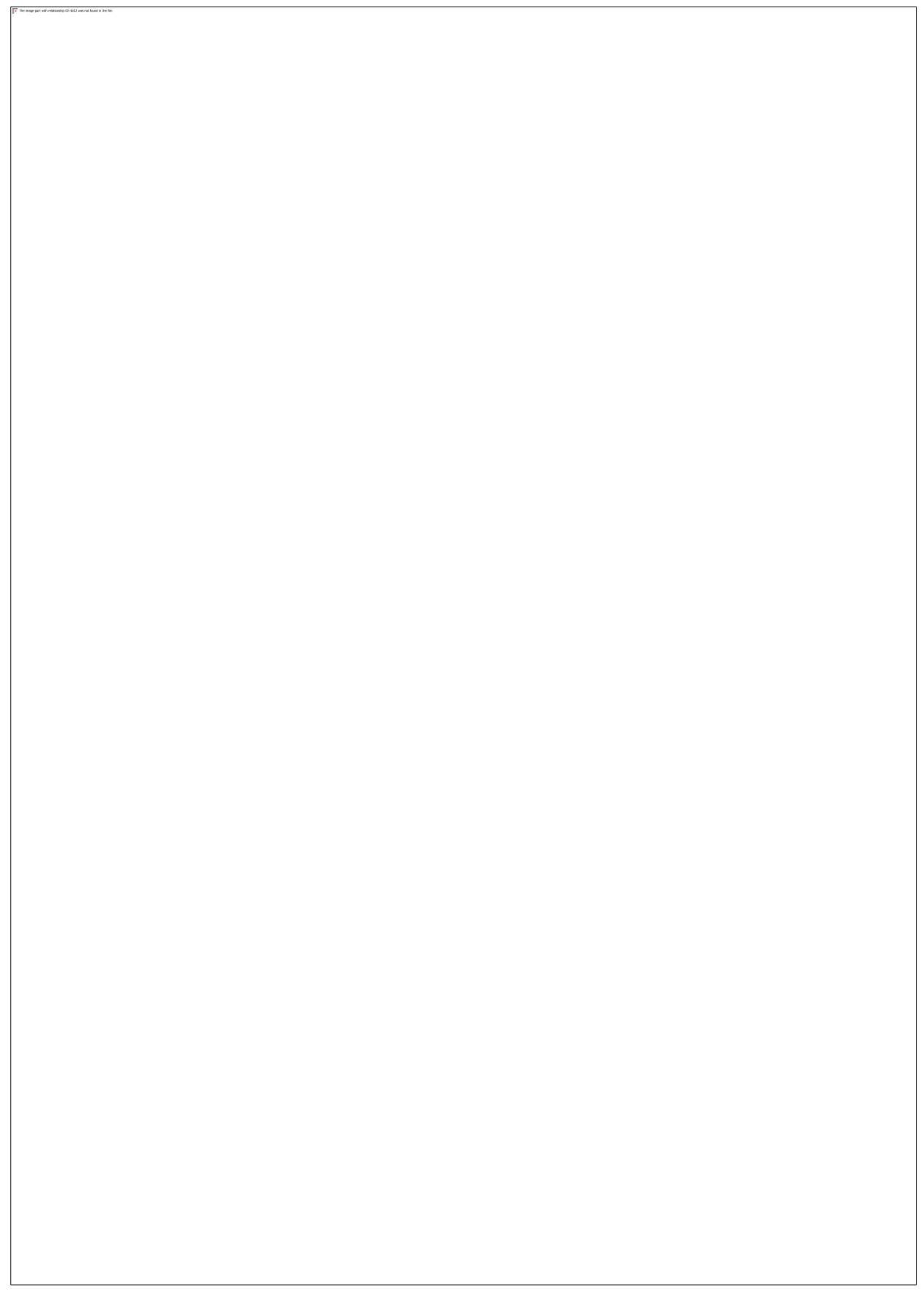

Figure 4. Correlation between the experimental enthalpies of formation of the selected species and their theoretically calculated values. Each marker is placed at the intersection of the theoretical and experimental value for each species. The dashed line represents the perfect correlation (i.e. when the experimental and theoretical values are identical). Full lines represent the least squares alignment of the data for each theoretical method employed when the enthalpies of formation are calculated with respect to the benzyl radical. In the case of the MP2 calculations, the dotted line represents the alignment when the enthalpies of formation are calculated with respect to toluene. The corresponding lines for G4 and M06 are not shown because they coincide with the ones with respect to the benzyl radical. Values in $\mathrm{kcal} / \mathrm{mol}$. 


\section{Tables with Captions}

Table 1. Errors of the calculated $\Delta_{f} H_{298}^{o}$ of simple radical and closed-shell species with respect to the experimental value, according to different reactions (in $\mathrm{kcal} / \mathrm{mol}$ ). Average errors for each reaction and for all methods are shown in the last lines, both including and excluding the MP2 results. Average errors for each method with respect to all the reactions are shown in the last columns. Upper and lower limits of these average errors are approximated by twice the standard deviation $( \pm 2 \sigma)$

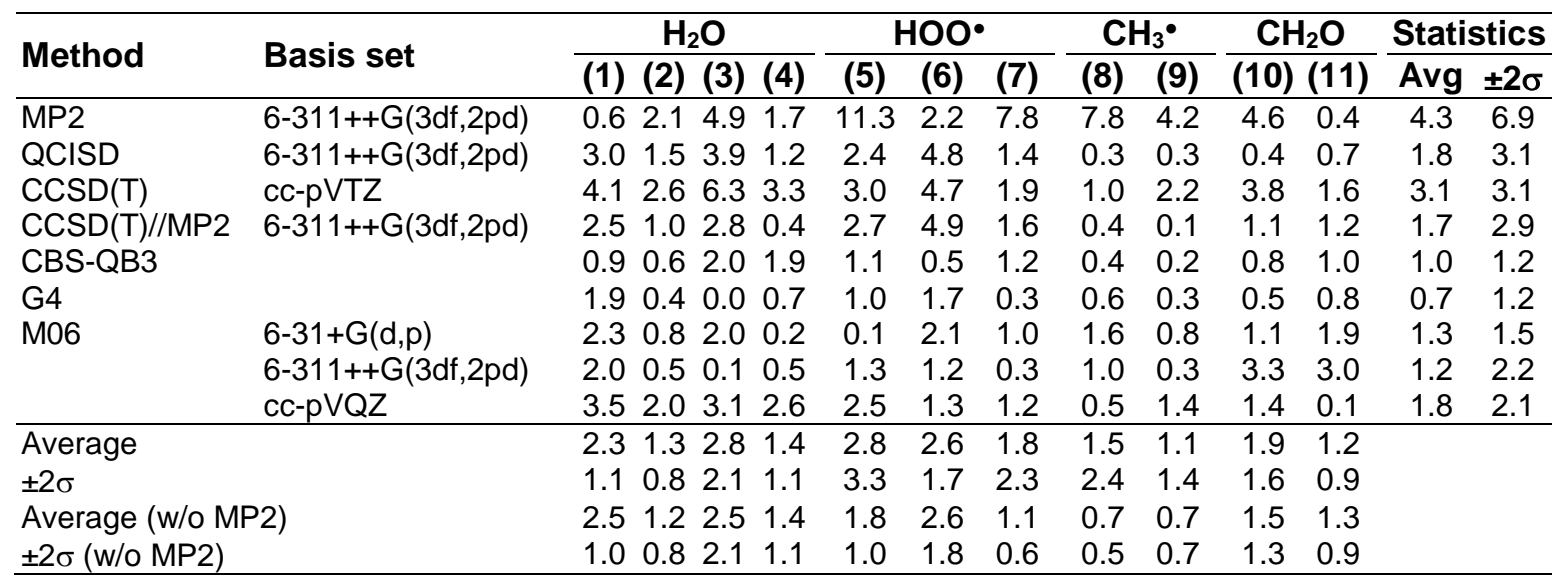

Table 2. Enthalpies of reaction and formation, as well as error of the theoretical enthalpy of formation of TR calculated using reactions (12) and (13). All values are in $\mathrm{kcal} / \mathrm{mol}$.

\begin{tabular}{|c|c|c|c|c|c|c|c|}
\hline \multirow[t]{2}{*}{ Method } & \multirow[t]{2}{*}{ Basis Set } & \multicolumn{3}{|c|}{ Reaction (1) } & \multicolumn{3}{|c|}{ Reaction (2) } \\
\hline & & $\Delta_{r} H_{298}^{o}$ & $\Delta_{f} H_{298}^{O}$ & Error & $\Delta_{r} H_{298}^{o}$ & $\Delta_{f} H_{298}^{o}$ & Error \\
\hline MP2 & $6-311++G(3 d f, 2 p d)$ & -7.7 & 71.1 & 21.4 & 10.5 & 75.3 & 25.6 \\
\hline CBS-QB3 & & -28.0 & 50.8 & 1.1 & -14.2 & 50.6 & 0.9 \\
\hline G4 & & -27.7 & 51.1 & 1.4 & -14.1 & 50.7 & 1.0 \\
\hline M06 & $6-31+G(d, p)$ & -29.4 & 49.3 & -0.4 & -16.3 & 48.5 & -1.2 \\
\hline & $6-311++G(3 d f, 2 p d)$ & -30.7 & 48.1 & -1.7 & -16.5 & 48.3 & -1.4 \\
\hline & $c c-p \vee Q Z$ & -29.1 & 49.7 & 0.0 & -16.6 & 48.3 & -1.5 \\
\hline Experimentala & & & $49.71 \pm 0$ & & & & \\
\hline
\end{tabular}

${ }^{a}$ Ref. [46] 
Table 3. Enthalpies of reaction and formation (in $\mathrm{kcal} / \mathrm{mol}$ ) for selected species

\begin{tabular}{|c|c|c|c|c|c|c|c|c|}
\hline \multirow[t]{2}{*}{ Species } & \multirow[t]{2}{*}{ Method } & \multirow[t]{2}{*}{ Basis Sets } & \multicolumn{4}{|c|}{ From Benzyl Radicala } & \multicolumn{2}{|c|}{ From Toluene ${ }^{b}$} \\
\hline & & & $\Delta_{r} H_{298}^{O}$ & $\Delta_{f} H_{298}^{O}$ & Error $\Delta$ & $\Delta_{r} H_{298}^{O}$ & $\Delta_{f} H_{298}^{O}$ & Error \\
\hline \multirow[t]{6}{*}{ I, Phenyl Radical } & \multicolumn{2}{|l|}{ CBS-QB3 } & 65.4 & 81.6 & 1.1 & 37.4 & 82.7 & 2.2 \\
\hline & & 63.2 & 79.4 & 1.1 & 35.5 & 80.8 & 0.3 \\
\hline & \multirow[t]{3}{*}{ M06 } & $6-31+G(d, p)$ & 60.5 & 76.7 & 3.8 & 31.0 & 76.3 & 4.2 \\
\hline & & $(3 d f, 2 p d)$ & 60.3 & 76.6 & 3.9 & 29.6 & 74.9 & 5.6 \\
\hline & & $c c-p \vee Q Z$ & 61.3 & 77.5 & 3.0 & 32.3 & \multirow{2}{*}{\multicolumn{2}{|c|}{$\begin{array}{r}77.5 \\
80.5 \pm 0.1\end{array}$}} \\
\hline & \multicolumn{2}{|l|}{ Exp. $^{c}$} & & & & & & \\
\hline \multirow[t]{6}{*}{ II, Benzoyl radical } & \multirow{2}{*}{\multicolumn{2}{|c|}{$\begin{array}{l}\text { CBS-QB3 } \\
\text { G4 }\end{array}$}} & -78.6 & 28.9 & 1.2 & -106.6 & 30.0 & 2.3 \\
\hline & & & -79.4 & 28.1 & 0.4 & -107.1 & 29.5 & 1.8 \\
\hline & \multirow[t]{3}{*}{ M06 } & $6-31+G(d, p)$ & -77.8 & 29.7 & 2.0 & -107.2 & 29.4 & 1.6 \\
\hline & & $(3 \mathrm{df}, 2 \mathrm{pd})$ & -79.5 & 28.1 & 0.3 & -110.2 & 26.4 & -1.3 \\
\hline & & $c c-p \vee Q Z$ & -74.9 & 32.6 & 4.9 & -103.9 & 32.6 & 4.9 \\
\hline & \multicolumn{2}{|c|}{ Exp. ${ }^{d}$} & & & & & $27.7 \pm 2.6$ & \\
\hline \multirow[t]{6}{*}{ III, Phenoxyl radical } & \multirow{2}{*}{\multicolumn{2}{|c|}{$\begin{array}{l}\text { CBS-QB3 } \\
\text { G4 }\end{array}$}} & -65.3 & 10.5 & -2.8 & -93.3 & 11.6 & -1.7 \\
\hline & & & -63.0 & 12.8 & -0.5 & -90.7 & 14.2 & 0.9 \\
\hline & M06 & $6-31+G(d, p)$ & -68.1 & 7.7 & -5.6 & -97.6 & 7.3 & -6.0 \\
\hline & & 3df,2pd) & -69.1 & 6.7 & -6.5 & -99.8 & 5.1 & -8.2 \\
\hline & & $c c-p \vee Q 2$ & -66.0 & 9.8 & -3.5 & -95.1 & 9.8 & -3.5 \\
\hline & Exp. $^{\mathrm{e}}$ & & & & & & $13.3 \pm 0.6$ & \\
\hline IV, Benzaldehyde & CBS-QB3 & & -51.0 & 10.2 & 1.4 & -78.9 & 9.1 & 0.3 \\
\hline & G4 & & -50.5 & 9.8 & 0.9 & -78.2 & 8.4 & -0.4 \\
\hline & M06 & $6-31+G(d, p)$ & -52.0 & 11.2 & 2.4 & -81.4 & 11.6 & 2.8 \\
\hline & & 3df,2pd) & -52.1 & 11.4 & 2.6 & -82.9 & 13.1 & 4.2 \\
\hline & & cc-pVQZ & -49.1 & 8.4 & -0.5 & -78.2 & 8.4 & -0.5 \\
\hline & Exp. ${ }^{\dagger}$ & & & & & & $8.8 \pm 0.2$ & \\
\hline V, Benzyl alcohol & CBS-QB3 & & -82.6 & -24.0 & 1.4 & -110.6 & -22.9 & 0.3 \\
\hline & G4 & & -80.5 & -21.9 & 0.7 & -108.3 & -20.5 & 2.1 \\
\hline & M06 & $6-31+G(d, p)$ & -80.2 & -21.5 & 1.1 & -109.6 & -21.9 & 0.7 \\
\hline & & 3df,2pd) & -80.3 & -21.7 & 0.9 & -111.0 & -23.3 & 0.7 \\
\hline & & $c c-p V Q Z$ & -79.3 & -20.7 & 1.9 & -108.4 & -20.7 & 1.9 \\
\hline & Exp. ${ }^{9}$ & & & & & & $-22.6 \pm 0.7$ & \\
\hline VI, Phenol & CBS-QB3 & & -33.3 & -24.2 & -1.2 & -61.3 & -23.2 & -0.1 \\
\hline & G4 & & -32.7 & -23.6 & -0.6 & -60.4 & -22.3 & 0.8 \\
\hline & M06 & $6-31+G(d$, & -35.0 & -25.9 & -2.9 & -64.4 & -26.3 & -3.3 \\
\hline & & $3 \mathrm{df}, 2 \mathrm{pd})$ & -36.0 & -27.0 & -3.9 & -66.7 & -28.6 & -5.6 \\
\hline & & cc-pVQZ & -34.3 & -25.3 & -2.3 & -63.4 & -25.3 & -2.3 \\
\hline & Exp. $^{\text {h }}$ & & & & & & $-23.0 \pm 0.2$ & \\
\hline VII, p-Benzoquinone & CBS-QB3 & & -96.6 & -29.7 & -2.0 & -124.5 & -28.6 & -0.9 \\
\hline & G4 & & -96.3 & -29.5 & -1.8 & -124.0 & -28.1 & -0.4 \\
\hline & M06 & $6-31+G(d, p)$ & -100.0 & -33.1 & -5.4 & -129.4 & -33.5 & -5.8 \\
\hline & & 3df,2pd) & -101.9 & -35.1 & -7.4 & -132.6 & -36.7 & -9.0 \\
\hline & & $c c-p V Q Z$ & -95.6 & -28.8 & -1.1 & -124.7 & -28.8 & -1.1 \\
\hline & Exp.' & & & & & & $-27.7 \pm 3.0$ & \\
\hline VIII, Catechol & CBS-QB3 & & -153.2 & -68.4 & -2.8 & -181.2 & -67.3 & -1.7 \\
\hline & G4 & & -149.7 & -65.0 & 0.7 & -177.4 & -63.6 & 2.1 \\
\hline & M06 & $6-31+G(d, p)$ & -154.1 & -69.3 & -3.6 & -183.5 & -69.7 & -4.0 \\
\hline & & $\mathrm{G}(3 \mathrm{df}, 2 \mathrm{pd})$ & -156.7 & -71.9 & -6.3 & -187.4 & -73.6 & -7.9 \\
\hline & & cc-pVQZ & -152.3 & -67.5 & -1.9 & -181.4 & -67.5 & -1.9 \\
\hline & Exp.j & & & & & & $-65.7 \pm 0.3$ & \\
\hline IX, Benzoic Acid & CBS-QB3 & & -189.7 & -73.3 & 0.3 & -217.7 & -72.2 & 0.8 \\
\hline & G4 & & -186.9 & -70.4 & 2.6 & -214.6 & -69.1 & 3.9 \\
\hline & M06 & $6-31+G(d, p)$ & -190.4 & -73.9 & 0.9 & -219.8 & -74.3 & 1.3 \\
\hline & & $\mathrm{G}(3 \mathrm{df}, 2 \mathrm{pd})$ & -191.8 & -75.3 & 2.3 & -222.5 & -77.0 & 4.0 \\
\hline & & $c c-p \vee Q Z$ & -186.3 & -69.8 & 3.2 & -215.3 & -69.8 & 3.2 \\
\hline
\end{tabular}

a Enthalpy of formation obtained on the basis of the experimental values of $\mathrm{TR}+\mathrm{O}_{2}$

${ }^{b}$ Enthalpy of formation obtained on the basis of the experimental values of $\mathrm{T}+\mathrm{OH}^{\bullet}+\mathrm{O}_{2}$

${ }^{c}$ Ref. [51] ${ }^{d}$ Ref. [53] ${ }^{\text {e }}$ Ref. [54] ${ }^{f}$ Ref. [42] g Ref. [66] ${ }^{\text {h }}$ Ref. [56] ' Ref. [58] ${ }^{\text {j }}$ Ref. [59] ${ }^{\text {k }}$ Ref. [60] 
Table 4. Enthalpies of reaction and formation (in $\mathrm{kcal} / \mathrm{mol}$ ) for the species with non-existent experimental data. Only values calculated at the CBS-QB3, G4 and M06/cc-pVQZ levels are shown. The full set of data is presented in Table SI2 in the Supplementary Information section.

\begin{tabular}{llrrrr}
\hline Species & Method & From the Benzyl Radical & From Toluene $^{\text {b }}$ \\
\hline & & $\Delta_{r} H_{298}^{O}$ & $\Delta_{f} H_{298}^{O}$ & $\Delta_{r} H_{298}^{o} \Delta_{f} H_{298}^{o}$ \\
\cline { 2 - 5 } X, Salicylic alcohol & CBS-QB3 & -53.4 & -40.6 & -81.3 & -69.3 \\
& G4 & -52.3 & -39.6 & -80.0 & -68.0 \\
XI. Benzyloxyl radical & M06 & -51.8 & -39.2 & -80.9 & -68.9 \\
& CBS-QB3 & 39.2 & 29.4 & 11.2 & 30.4 \\
& G4 & 37.1 & 27.2 & 9.4 & 28.6 \\
XII, Hydroxyphenyl radical & M06 & 38.6 & 28.7 & 9.5 & 28.7 \\
& CBS-QB3 & -36.5 & 39.3 & -64.5 & 40.4 \\
& G4 & -37.6 & 38.2 & -65.3 & 39.6 \\
XIII, Benzo[b] oxetane & M06 & -40.7 & 35.1 & -69.7 & 35.1 \\
& CBS-QB3 & -18.8 & 22.0 & -46.8 & 23.0 \\
XIV, Spiro [1,2-dioxetane phenyl] radical CBS-QB3 & -17.9 & 22.8 & -45.7 & 24.2 \\
& G4 & -17.0 & 23.7 & -46.1 & 23.7 \\
XV, p-Hydroxy cyclohexa-2,5-dienone & G4 & 3.0 & 52.7 & -25.0 & 53.8 \\
& CBS-QB3 & -127.1 & -43.4 & -156.2 & -42.4 \\
& G4 & -125.3 & -41.6 & -154.0 & -40.2 \\
XVI, Benzyl peroxyl radical & M06 & -125.5 & -41.8 & -155.6 & -41.8 \\
& CBS-QB3 & -23.0 & 26.7 & -50.9 & 27.8 \\
& G4 & -23.4 & 26.3 & -51.2 & 27.6 \\
& & -18.8 & 30.9 & -47.9 & 30.9 \\
\hline
\end{tabular}

a Enthalpy of formation obtained using the experimental values of $\mathrm{TR}+\mathrm{O}_{2}$ as reference

${ }^{b}$ Enthalpy of formation obtained using the experimental values of $\mathrm{T}+\mathrm{OH}^{\bullet}+\mathrm{O}_{2}$ as reference

Table 5. Species with previously unknown enthalpies of formation, reactions used to derive the values calculated in this paper and recommended enthalpies of formation for these species

\begin{tabular}{|c|c|c|c|c|}
\hline \multicolumn{2}{|r|}{ Species } & \multicolumn{2}{|l|}{ Reactions } & \multirow{2}{*}{$\begin{array}{c}\begin{array}{c}\Delta_{f} H_{298}^{o} \\
(\mathrm{kcal} / \mathrm{mol})\end{array} \\
-69.7 \pm 3.4\end{array}$} \\
\hline $\mathrm{X}$ & $\begin{array}{l}\text { Salicylic alcohol } \\
\text { (2-hydroxy benzyl alcohol) }\end{array}$ & $\begin{array}{l}\mathrm{TR}+\mathrm{O}_{2}+\mathrm{H}_{2} \mathrm{O} \rightarrow \mathrm{X}+\mathrm{OH}^{\bullet} \\
\mathrm{T}+\mathrm{O}_{2} \rightarrow \mathrm{X}\end{array}$ & $\begin{array}{l}(34) \\
(35)\end{array}$ & \\
\hline $\mathrm{XI}$ & $\begin{array}{l}\text { Benzyloxyl radical } \\
\left(\lambda^{1} \text {-oxidanyl methylbenzene) }\right.\end{array}$ & $\begin{array}{l}\mathrm{TR}+\mathrm{O}_{2} \rightarrow \mathrm{XI}+\mathrm{O} \\
\mathrm{T}+\mathrm{O}_{2}+\mathrm{OH}^{\bullet} \rightarrow \mathrm{XI}+\mathrm{O}+\mathrm{H}_{2} \mathrm{O}\end{array}$ & $\begin{array}{l}(36) \\
(37)\end{array}$ & $28.4 \pm 3.4$ \\
\hline XII & Hydroxyphenyl radical & $\begin{array}{l}\mathrm{TR}+\mathrm{O}_{2} \rightarrow \mathrm{XII}+\mathrm{CH}_{2} \mathrm{O} \\
\mathrm{T}+\mathrm{O}_{2}+\mathrm{OH}^{\bullet} \rightarrow \mathrm{XII}+\mathrm{CH}_{2} \mathrm{O}+\mathrm{H}_{2} \mathrm{O}\end{array}$ & $\begin{array}{l}(38) \\
(39)\end{array}$ & $37.3 \pm 3.4$ \\
\hline XIII & Benzo[b]oxetane & $\begin{array}{l}\mathrm{TR}+\mathrm{O}_{2} \rightarrow \mathrm{XIII}+\mathrm{OH}^{\bullet} \\
\mathrm{T}+\mathrm{O}_{2} \rightarrow \mathrm{XIII}+\mathrm{H}_{2} \mathrm{O}\end{array}$ & $\begin{array}{l}(40) \\
(41)\end{array}$ & $23.7 \pm 3.4$ \\
\hline XIV & $\begin{array}{l}\text { Spiro [1,2-oxoetane phenyl] } \\
\text { radical }\end{array}$ & $\begin{array}{l}\mathrm{TR}+\mathrm{O}_{2} \rightarrow \mathrm{XIV} \\
\mathrm{T}+\mathrm{O}_{2}+\mathrm{OH}^{\bullet} \rightarrow \mathrm{XIV}+\mathrm{H}_{2} \mathrm{O}\end{array}$ & $\begin{array}{l}(42) \\
(43)\end{array}$ & $57.3 \pm 3.4$ \\
\hline$X V$ & $\begin{array}{l}\text { p-Hydroxy cyclohexan-2,5- } \\
\text { dienone }\end{array}$ & $\begin{array}{l}\mathrm{TR}+\mathrm{O}_{2}+\mathrm{OH}^{\bullet} \rightarrow \mathrm{XV}+\mathrm{CH}_{2} \mathrm{O} \\
\mathrm{T}+\mathrm{O}_{2}+2 \mathrm{OH}^{\bullet} \rightarrow \mathrm{XV}+\mathrm{CH}_{2} \mathrm{O}+\mathrm{H}_{2} \mathrm{O}\end{array}$ & $\begin{array}{l}(44) \\
(45)\end{array}$ & $-42.1 \pm 3.4$ \\
\hline $\mathrm{XVI}$ & Benzylperoxyl radical & $\begin{array}{l}\mathrm{TR}+\mathrm{O}_{2} \rightarrow \mathrm{XVI} \\
\mathrm{T}+\mathrm{O}_{2}+\mathrm{OH}^{\bullet} \rightarrow \mathrm{XVI}+\mathrm{H}_{2} \mathrm{O}\end{array}$ & $\begin{array}{l}(46) \\
(47)\end{array}$ & $28.5 \pm 3.4$ \\
\hline
\end{tabular}

